\title{
Using Meta-Analysis and GIS for Value Transfer and Scaling Up: Valuing Climate Change Induced Losses of European Wetlands
}

\author{
Luke M. Brander • Ingo Bräuer • Holger Gerdes · Andrea Ghermandi • \\ Onno Kuik · Anil Markandya • Ståle Navrud • Paulo A. L. D. Nunes • \\ Marije Schaafsma · Hans Vos · Alfred Wagtendonk
}

Accepted: 11 December 2011 / Published online: 30 December 2011

(C) The Author(s) 2011. This article is published with open access at Springerlink.com

\begin{abstract}
There is growing policy and academic interest in transferring ecosystem service values from existing valuation studies to other ecosystem sites at a large geographic scale. Despite the evident policy demand for this combined transfer and "scaling up" of values, an approach to value transfer that addresses the challenges inherent in assessing ecosystem changes at a national or regional level is not available. This paper proposes a methodology for scaling up ecosystem service values to estimate the welfare effects of ecosystem change at this larger geographical scale. The methodology is illustrated by applying it to value the impact of climate change on European wetlands for the period 2000-2050. The proposed methodology makes use of meta-analysis to produce a value function. The parameters of the value function include spatial variables on wetland size and abundance, GDP per capita, and population. A geographic information system is used to construct a database of wetland
\end{abstract}

\section{M. Brander (四)}

Unit 2408, Block F, 9-11 Hong Shing Street, Kornhill, Quarry Bay, Hong Kong

e-mail: lukebrander@gmail.com

I. Bräuer

Potsdam Institute for Climate Impact Research, Telegraphenberg A 31, 14473 Potsdam, Germany

e-mail: ingo.braeuer@pik-potsdam.de

H. Gerdes

Ecologic Institute, Pfalzburger Strasse 43/44, 10717 Berlin, Germany

e-mail: holger.gerdes@ecologic.eu

A. Ghermandi

Cà Foscari University of Venice, Dorsoduro 3246, 30123 Venice, Italy

e-mail: andrea.ghermandi@unive.it

O. Kuik · M. Schaafsma - A. Wagtendonk

Institute for Environmental Studies, VU University Amsterdam, De Boelelaan 1087,

1018 HV Amsterdam, The Netherlands

e-mail: onno.kuik@ivm.vu.nl

A. Wagtendonk

e-mail: alfred.wagtendonk@ivm.vu.nl 
sites in the case study region with information on these spatial variables. Site-specific ecosystem service values are subsequently estimated using the meta-analytic value function. The proposed method is shown to enable the adjustment of transferred values to reflect variation in important spatial variables and to account for changes in the stock of ecosystems.

Keywords Value transfer $\cdot$ Meta-analysis · GIS · Scaling up · Wetlands

\section{Introduction}

It is well established that human well-being is dependent upon ecosystem services provided by nature (Millennium Ecosystem Assessment 2005; TEEB 2010). The term ecosystem services (ES) covers the broad range of connections between the environment and human well-being, including: supporting services (e.g. nutrient cycling, soil formation), provisioning services (e.g. food, fresh water), regulating services (e.g. climate regulation, flood attenuation), and cultural services (e.g. recreational, spiritual, aesthetic) (Millennium Ecosystem Assessment 2005). Ecosystems face a variety of pressures resulting from population growth, urbanisation, and climate change but due to the public good characteristics of many ES, they are typically under-valued in both private and public decision-making relating to their use and conservation. As a result many ecosystems are continually being degraded causing the provision of ecosystem services to decline.

Policy makers require to be informed about the economic consequences of the decisions they take. Cost-benefit analysis, firmly grounded in economic theory, has traditionally been a major tool to inform politicians, although it is limited by the need for monetised inputs. In the case of climate change, however, and probably even more pronounced in the case of ecosystem conservation, goods and services not traded in markets and therefore non-priced are dominant components in any economic assessment. In response to this need for information on the value of environmental impacts, there is a large and growing literature on the valuation of non-market commodities, including goods and services provided by ecosystems. Primary valuation research, however, is time and money intensive and results are limited. For this reason there is both a policy and academic interest in transferring values from existing

\footnotetext{
A. Markandya

Basque Centre for Climate Change, Alameda Urquijo 4, 4a, 48008 Bilbao, Bizkaia, Spain e-mail: anil.markandya@bc3research.org
}

S. Navrud

Department of Economics and Resource Management, Norwegian University of Life Sciences, $1432 \AA$ Ås, Norway

e-mail: stale.navrud@umb.no

P. A. L. D. Nunes

Research Program on Marine Economics, The Mediterranean Science Commission-CIESM,

16 Boulevard de Suisse, Monte Carlo, Principality of Monaco

e-mail: pnunes@ciesm.org

\section{Schaafsma}

CSERGE, University of East Anglia, Norwich, NR4 7TJ, UK

e-mail: M.Schaafsma@uea.ac.uk

\section{H. Vos}

European Environment Agency, Kongens Nytorv 6, 1050 Copenhagen K, Denmark

e-mail: hansbvos@gmail.com 
valuation studies to other, so-called policy sites (Navrud and Ready 2007). Value (or benefit) transfer is the procedure of estimating the value of an ecosystem of current policy interest (policy site) by assigning an existing valuation estimate for a similar ecosystem (study site). Value transfer methods can be divided into three categories: unit value transfer (without or with adjustments; usually for income differences); value function transfer (using an estimated value function from an individual primary study); and meta-analytic function transfer (using a value function estimated from the results of multiple primary studies). For a number of reasons the application of any of these value transfer methods may result in significant transfer errors, i.e. transferred values may differ significantly from the actual value of the ecosystem under consideration. There exists a sizeable literature that tests the accuracy of value transfer, of which Rosenberger and Stanley (2006), Eshet et al. (2007), and Johnston and Rosenberger (2009) provide useful overviews. Although some studies find very high transfer errors (e.g. Downing and Ozuna 1996; Kirchhoff 1998), most studies find transfer errors in the range of 0-100\% even in international value transfers (Ready and Navrud 2006). The required accuracy of value transfer is context specific, with arguably a higher requirement for accuracy in the case of setting compensation payments for environmental damage or in cost-benefit analysis of specific investments than for more general policy settings.

Assessments of environmental impacts at large geographic scales, such as the Stern review on the economics of climate change (Stern 2007), the Cost of Policy Inaction study on biodiversity (Braat and ten Brink 2008), and The Economics of Ecosystems and Biodiversity programme (TEEB 2010) bring a new dimension to value transfer. All three studies analyse global economic effects. In this study we make an important distinction between value transfers that estimate the value of a single or small number of individual ecosystem sites and the "scaling-up" of values that provide estimates for all ecosystem sites within a large geographic area. The term "scaling up" is used to describe the transfer of values that have been estimated for localised changes in individual ecosystem sites to assess the value of changes in multiple ecosystem sites within a large geographic area (e.g. country or region). While value transfer to a single ecosystem site is already complex, scaling up values is accompanied by additional complexity and methodological difficulties.

At the level of individual ecosystem sites, marginal unit values for ecosystem services are likely to vary with the characteristics of the ecosystem site (area, integrity, and type of ecosystem), beneficiaries (number, income, preferences), and context (availability of substitute and complementary sites and services). The transfer of values to an individual ecosystem site needs to account for variation in these characteristics between study sites and the policy site. Localised changes in the extent of an individual ecosystem patch may be adequately evaluated in isolation from the rest of the stock of the resource, which is effectively assumed to be constant. The effects of phenomena, such as climate change, that cause changes in all or a large proportion of ecosystem sites within a region require, however, that the effect of changes in the stock of the ecosystem on the marginal values of individual sites is taken into account. When valuing simultaneous changes in multiple ecosystem sites within a region (i.e. scaling up values), it is not sufficient to estimate the value of individual ecosystem site values and aggregate without accounting for the changes that are occurring across the stock of the resource. As an environmental resource becomes scarcer, its marginal value will tend to increase (Fisher et al. 2008). This means that multiplying a constant marginal value by the change in area of an ecosystem site, as is usually done in scaling up exercises, is likely to underestimate the value of the change (Bockstael et al. 2000). This point is elaborated upon further in Fig. 1, Sect. 2. One of the criticisms of the analysis by Costanza et al. (1997), which "scaled up" values from study site information to the global scale, is that their methodology 
did not account for the (implicit in their analysis) simultaneous change in all other ecosystems sites. It is this challenge that we address in this paper.

In this paper we propose a methodology for scaling up values for changes in the stock of ecosystems at large geographic scales using a meta-analytic value function combined with spatial data derived from a geographic information system (GIS). Importantly, the value function includes a parameter capturing the abundance of similar ecosystem sites in the vicinity of each study site, which can be used to adjust marginal values following changes in resource availability. We illustrate this methodology in a case study of the impact of climate change on European wetlands for the period 2000-2050.

The structure of the remainder of the paper is as follows. Section 2 describes our proposed methodology for using meta-analysis and GIS to estimate the value of ecosystem change at a large geographic scale. Section 3 illustrates this method with a case study on the impact of climate change on wetlands in Europe, and includes a description of the meta-analysis of wetland values, the GIS procedures used to construct spatial information on wetland sites, and the valuation results. Section 4 provides a discussion of the sources of uncertainty in such an analysis. Finally, Sect. 5 provides conclusions.

\section{Methodology for Scaling Up Ecosystem Service Values}

In this section we outline our proposed method for using value transfer to estimate the value of changes in ecosystem service provision at large geographic scales. Conceptually, the economic value of a loss in the provision of an ecosystem service can be expressed as the area under the social Hicksian demand curve for the service that is bounded by the prechange level of provision and the post-change level of provision, everything else being equal. Figure 1 shows a downward sloping demand curve for the flow of ecosystem services. The value of a loss of area (e.g. from A to B) can be evaluated as the area under the demand curve. If this change is valued simply as the change in ecosystem extent (A-B) multiplied by a constant marginal value evaluated at the pre-change level of resource availability $\left(\mathrm{P}^{\mathrm{A}}\right)$, the welfare change associated with the loss in area will be underestimated (indicated by the shaded triangle in Fig. 1).

We propose the use of a meta-analytic value function to obtain information on how marginal values vary with changes in the abundance of an ecosystem. By including an explanatory variable in the meta-regression function that captures the abundance of similar ecosystem sites in the vicinity of each study site, the estimated coefficient on this variable provides us with a means of adjusting transferred values to account for changes in the stock of the ecosystem. This approach requires sufficient variation in the underlying primary valuation data on resource availability between study sites to be able to estimate this effect on site specific marginal values.

Meta-analytic function transfer offers a relatively accurate approach to value transfer by allowing differences in site and context variables to be controlled for (Rosenberger and Phipps 2007). As such it is generally understood to produce lower transfer errors than (adjusted) unit value transfer and value function transfer (Johnston et al. 2005; Moeltner et al. 2007; Shrestha et al. 2007). In addition, this approach is well suited to valuing large numbers of diverse policy sites in that the estimated value function can be applied to a database containing information on ecosystem and socio-economic characteristics of each policy site. The limitations and challenges faced in using meta-analytic functions for value transfer are discussed in Sect. 4. 


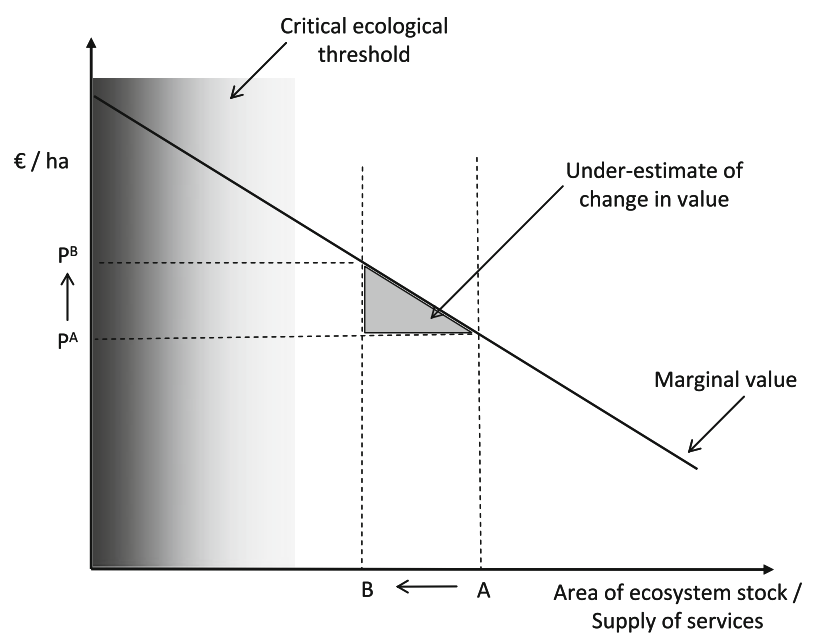

Fig. 1 Valuing changes in the provision of ecosystem services. (adapted from Turner et al. 2003)

The steps in our proposed method for transferring values for changes in ecosystem stocks are:

1. Construct a database of primary valuation estimates for the ecosystem of interest. Standardise value estimates in terms of monetary units per unit area of ecosystem per year (e.g. US\$ per hectare per year). ${ }^{1}$

2. Estimate a meta-analytic value function for the ecosystem in question. The dependent variable in the value function is the standardised value (defined in step 1). The estimated value function should include explanatory variables that capture study site characteristics (i.e. size, services provided); context characteristics (i.e. abundance of the ecosystem in the region); socio-economic characteristics of beneficiaries (i.e. size of relevant population, income); and study characteristics (i.e. valuation method used to produce each primary value estimate included in the meta-analysis). ${ }^{2}$

3. Construct a database of policy sites in the region of interest using a GIS to include information on the variables in the meta-analytic value function (i.e. size of each ecosystem site, abundance of the ecosystem within the vicinity of each site, population in the vicinity of each site, and income level of the population). The database should contain values

\footnotetext{
1 We propose to transfer values on the basis of units of area of individual ecosystem patches. An alternative and commonly used approach is to transfer values to individual beneficiaries and then aggregate over the economic constituency that hold values for the resource in question. In this approach, WTP per person or per household is transferred and can be adjusted for spatially referenced site and beneficiary characteristics, including distance to the valued site (Bateman et al. 2006). We opt to transfer values to individual ecosystem sites rather than to individual beneficiaries for two reasons. Firstly, several valuation methods do not produce estimates of WTP per person (e.g. production function and net factor income methods). Similarly, some ecosystem services are not straightforwardly expressed in per beneficiary terms (e.g. support to commercial fisheries, carbon sequestration). Secondly, the identification of the appropriate economic constituency to which per beneficiary values can be transferred is often problematic due to a lack of prior information on the spatial extent of the market for policy sites. In our proposed method we account for differences in economic constituency between policy sites by including adjustment factors for population and income levels in the value function (see step 2).

2 Smith and Pattanayak (2002) and Nelson and Kennedy (2009) provide best practice guidelines for conducting meta-analyses of the economic valuation literature and address the additional requirements for value transfer.
} 
for each of these variables at pre- and post-change states for each policy site (e.g. at two different points in time or for two different policy scenarios).

4. For each policy site, estimate the marginal value per hectare at the pre-change and post-change levels. This is done by substituting in pre- and post-change variable values into the meta-analytic value function. Calculate the average of the pre-change and postchange marginal values per hectare for each site in order to approximate the average per hectare value of the area that is lost (i.e. the average of $\mathrm{P}^{\mathrm{A}}$ and $\mathrm{P}^{\mathrm{B}}$ in Fig. 1). ${ }^{3}$

5. Multiply the value per hectare for each site by the change in area for each site. This gives an estimate of the value of the change in size of each ecosystem site.

6. Aggregate the estimated changes in value of individual policy sites to the regional or national level. This gives the annual value of the change in ecosystem service provision at that scale. ${ }^{4}$

Some important limitations on the scale at which this methodology can be applied are recognised. Firstly, changes in the supply of ecosystem services can be evaluated in this way for cases in which the provision of services is proportional to the geographic size of ecosystem sites. The provision of ecosystem services, however, often follows a complex relationship with ecosystem size. In the extreme, the relationship between ecosystem functioning, provision of services and ecosystem scale can completely break down, i.e. in the case that an ecological threshold is reached (indicated by the shaded area in Fig. 1). An ecological threshold is usually understood to be the point at which an ecosystem ceases to function (Scheffer et al. 2001). As an ecosystem is altered (loss of area, species, material/water input, etc.) its ecological functioning and provision of services may gradually decline up to a point where the ecosystem collapses and the provision of ecosystem services abruptly cease- the area of ecosystem or level of disturbance at which this occurs is a threshold (Perrings and Pearce 1994). There is usually a high degree of uncertainty regarding the nature and location of ecological thresholds and it is difficult (and, when the change occurs sufficiently far from the threshold, not relevant) to define critical thresholds for every ecosystem service (Fisher et al. 2008). Since our proposed method implicitly assumes that the provision of all ecosystem services is proportional to the geographic size of the ecosystem sites, it does not apply to changes in ecosystem service provision that exceed ecological thresholds. Indeed, it is no longer possible to obtain meaningful economic values for changes in the stock of critical natural capital that exceed ecological thresholds (Mullan and Kontoleon 2008).

Secondly, primary valuation studies generally measure the value of ecosystem services around present levels of overall provision (studies generally focus on single sites, with the implicit or explicit assumption that the level of provision of services from substitute sites is not changed) and the current availability of substitutes is therefore reflected in the value of the study site. The value of very large changes in resource availability is therefore beyond the domain of our observations. This makes the assessment of the value of a very large change or complete loss of an ecosystem in a region impossible. Our proposed method for valuing changes in ecosystem service provision is therefore applicable to measuring changes in the stocks of ecosystems but not changes of a magnitude that exceed ecological thresholds or

3 This step assumes a linear demand curve. Provided that the evaluated change in the stock of the resource does not exceed an ecological threshold and is at least substantially less than a total loss of the ecosystem stock, linearisation of the demand curve will in general be a reasonable approximation to the unknown true curvature of the demand curve. The limitations are discussed further in the main text.

4 It should be noted that our proposed approach to scaling up values is to estimate the value of flows of ecosystem services produced by the stock of an ecosystem. The present value of the stock can be calculated as the capitalised value of the flow of ecosystem services. Similarly the value of a change in the stock of an ecosystem is the capitalised value of the associated change in flow of ecosystem services. 
result in resource scarcity that is not represented by study sites valued in the available primary valuation literature.

\section{Application to Value Changes in the Extent of European Wetlands}

In this section we illustrate the methodology set out in Sect. 2 to estimate the value of changes in wetland ecosystem services due to climate change in Europe for the period 20002050. Section 3.1 describes the meta-analytic value function for wetland ecosystem services; Sect. 3.2 provides a description of the GIS procedures and the spatial data on wetlands in the case study region; Sect. 3.3 presents the results and provides a discussion.

\subsection{Meta-analytic Value Function for Wetlands}

The data set used to estimate the meta-analytic value transfer function contains 222 independent observations of wetland values for temperate climate zone wetlands (mainly from the US and Europe). These data are taken from 120 primary valuation studies, so in many cases we obtain multiple value estimates from a single study. This was only done if estimates from the same study represent genuinely independent values, i.e. obtained using different data, valuation methodology, and/or measure different ecosystem services. Values reported in the literature include estimates for the total loss of individual wetland sites, marginal changes in wetland area, the total value of the flow of services (without reference to any change in the resource), and marginal changes in wetland quality. Value estimates are included in the metaanalysis if they can be standardised to our chosen definition for the dependent variable, i.e. US\$/hectare/year. Value estimates for changes in wetland quality are therefore not included in the data. For a complete overview of this data set regarding sources and standardisation of values see Ghermandi et al. (2010). The data used in the present analysis are for temperate climate zone wetlands only, since the case study is on European wetlands, and are therefore a subset of the data described in Ghermandi et al. (2010).

The meta-analytic regression model is given in Eq. 1.

$$
\ln \left(y_{i}\right)=a+b_{S} X_{S i}+b_{W} X_{W i}+b_{C} X_{C i}+u_{i}
$$

The dependent variable $(y)$ in the meta-regression equation is the vector of the wetland values standardized to 2003 US\$ per hectare per year. The subscript $i$ assumes values from 1 to 222 (number of observations), $a$ is the constant term, $b_{S}, b_{W}$ and $b_{C}$ are the coefficients of the explanatory variables and $u$ is a vector of residuals. The explanatory variables consist of three categories giving characteristics of: (i) the valuation study $X_{S}$, (ii) the valued wetland $X_{W}$, and (iii) the socio-economic and geographical context $X_{C}$. Table 1 presents the full list of variables included in the analysis with the mean and standard deviation of each. The meta-regression results are presented in Table 2. A series of diagnostic tests were performed in order to test the robustness of the OLS estimation. The Shapiro-Wilk test ( $p$ level $=0.621$ ) does not reject the assumption of normally distributed residuals. Similarly, the null hypothesis of homogenous variance of the residuals cannot be rejected by White's test for heteroskedasticity (White's statistic $=12.876$ ). Regarding model specification, the regression specification error test for omitted variables (RESET statistic $=0.043)$ does not suggest specification errors.

The estimated coefficients on the context variables all have expected signs. The coefficient on the wetland abundance variable (measured as the area of wetland within a $50 \mathrm{~km}$ radius of the valued wetland site) is negative, albeit not quite statistically significant at the 
Table 1 Dependent and explanatory variables included in the meta-regression model

\begin{tabular}{|c|c|c|c|}
\hline & Variable & Mean & $\begin{array}{l}\text { Standard } \\
\text { deviation }\end{array}$ \\
\hline Dependent variable & Wetland value, US\$/ha/year (ln) & 5.893 & 2.385 \\
\hline \multicolumn{4}{|l|}{ Study variables } \\
\hline \multirow[t]{9}{*}{ Valuation method } & Contingent valuation & 0.269 & 0.444 \\
\hline & Choice experiment & 0.031 & 0.175 \\
\hline & Hedonic pricing & 0.022 & 0.148 \\
\hline & Travel cost method & 0.170 & 0.377 \\
\hline & Replacement cost & 0.206 & 0.406 \\
\hline & Net factor income & 0.143 & 0.351 \\
\hline & Production function & 0.058 & 0.235 \\
\hline & Market prices & 0.161 & 0.369 \\
\hline & Opportunity cost & 0.040 & 0.197 \\
\hline Marginal value & Marginal valuation & 0.166 & 0.373 \\
\hline \multicolumn{4}{|l|}{ Wetland variables } \\
\hline \multirow[t]{5}{*}{ Wetland type } & Inland marshes & 0.762 & 0.427 \\
\hline & Peatbogs & 0.054 & 0.226 \\
\hline & Salt marshes & 0.166 & 0.373 \\
\hline & Intertidal mudflats & 0.121 & 0.327 \\
\hline & Saline wetlands & 0.076 & 0.266 \\
\hline Wetland size & Wetland size before change, ha (ln) & 8.913 & 2.864 \\
\hline \multirow[t]{11}{*}{ Ecosystem service } & Flood control and storm buffering & 0.148 & 0.356 \\
\hline & Surface and groundwater supply & 0.126 & 0.332 \\
\hline & Water quality improvement & 0.175 & 0.381 \\
\hline & Commercial fishing and hunting & 0.193 & 0.395 \\
\hline & Recreational hunting & 0.215 & 0.412 \\
\hline & Recreational fishing & 0.197 & 0.399 \\
\hline & Harvesting of natural materials & 0.121 & 0.327 \\
\hline & Fuel wood & 0.036 & 0.186 \\
\hline & Non-consumptive recreation & 0.287 & 0.453 \\
\hline & Amenity and aesthetics & 0.166 & 0.373 \\
\hline & Natural habitat and biodiversity & 0.139 & 0.347 \\
\hline \multicolumn{4}{|l|}{ Context variables } \\
\hline & Real GDP per capita, US\$ (ln) & 9.509 & 1.346 \\
\hline & Population in $50 \mathrm{~km}$ radius ( $\mathrm{ln}$ ) & 12.815 & 1.385 \\
\hline & Wetland area in $50 \mathrm{~km}$ radius, ha $(\mathrm{ln})$ & 11.083 & 2.014 \\
\hline
\end{tabular}

$N B$ Variables without an explicit dimension are dummy variables that take on the value 1 if applicable and 0 if not

$10 \%$ level, indicating that as wetland abundance increases, the value of a hectare of wetland tends to be lower. ${ }^{5}$ Similarly, the coefficient on size of the wetland site is negative, indicating diminishing returns to scale with wetland size. In other words, the value of adding an addi-

5 The scale at which the abundance variable is defined $(50 \mathrm{~km})$ is empirically determined in the meta-analysis. We defined the abundance variable at three different scales $(20,50$ and $100 \mathrm{~km})$, tested them separately in the 
Table 2 Meta-regression model of wetland values

\begin{tabular}{|c|c|c|c|}
\hline & Variable & Coefficient & $p$ value \\
\hline & (constant) & -0.970 & 0.709 \\
\hline \multirow[t]{10}{*}{ Study variables } & Contingent valuation & 0.317 & 0.625 \\
\hline & Choice experiment & -0.524 & 0.581 \\
\hline & Hedonic pricing & $-2.328^{* *}$ & 0.043 \\
\hline & Travel cost method & -0.705 & 0.261 \\
\hline & Replacement cost & -0.383 & 0.538 \\
\hline & Net factor income & -0.125 & 0.843 \\
\hline & Production function & -0.091 & 0.896 \\
\hline & Market prices & -0.215 & 0.712 \\
\hline & Opportunity cost & -1.164 & 0.165 \\
\hline & Marginal valuation & $0.828^{*}$ & 0.053 \\
\hline \multirow[t]{16}{*}{ Wetland variables } & Inland marshes & -0.211 & 0.726 \\
\hline & Peatbogs & $-2.266^{* * *}$ & 0.004 \\
\hline & Salt marshes & $0.073^{*}$ & 0.901 \\
\hline & Intertidal mudflats & -0.239 & 0.672 \\
\hline & Wetland size before change, ha (ln) & $-0.218^{* * *}$ & 0.000 \\
\hline & Flood control and storm buffering & 0.626 & 0.169 \\
\hline & Surface and groundwater supply & -0.106 & 0.828 \\
\hline & Water quality improvement & 0.514 & 0.288 \\
\hline & Commercial fishing and hunting & 0.042 & 0.917 \\
\hline & Recreational hunting & $-1.355^{* * *}$ & 0.002 \\
\hline & Recreational fishing & -0.119 & 0.786 \\
\hline & Harvesting of natural materials & -0.153 & 0.732 \\
\hline & Fuel wood & -0.959 & 0.198 \\
\hline & Non-consumptive recreation & 0.218 & 0.626 \\
\hline & Amenity and aesthetics & 0.432 & 0.370 \\
\hline & Natural habitat and biodiversity & $1.211^{* *}$ & 0.012 \\
\hline \multirow[t]{3}{*}{ Context variables } & Real GDP per capita, US\$ (ln) & $0.430^{* * *}$ & 0.004 \\
\hline & Population in $50 \mathrm{~km}$ radius ( $(\mathrm{n})$ & $0.503^{* * *}$ & 0.000 \\
\hline & Wetland area in $50 \mathrm{~km}$ radius, ha (ln) & -0.125 & 0.118 \\
\hline
\end{tabular}

OLS results. Adj. $R^{2}=0.36 . \mathrm{N}=222$. Statistical significance is indicated with ${ }^{* * *}, * *$, and $*$ for 1,5 , and $10 \%$ levels respectively

tional hectare to a large wetland is worth less than adding an additional hectare to a small wetland. As expected, the coefficients on GDP per capita and population are both positive and statistically significant, indicating a positive relationship between these variables and

Footnote 5 continued

meta-regression, and selected the scale with the highest explanatory power. We did not assume, a priori, that abundance would have either substitution or complementary effects at a given scale but simply tested the (sign of the) effect in the meta-analysis. The case study is conducted at the European scale but it is not assumed that substitution/complementary effects operate at this scale. 
wetland values. ${ }^{6}$ The coefficient on the dummy variable indicating that a value estimate is for a marginal change is positive and statistically significant at the $10 \%$ level, i.e. marginal per hectare values tend to be higher than average per hectare values. ${ }^{7}$ This result is unexpected given that marginal values are lower than average values if unit values decline with increasing abundance of the resource. One possible explanation is that marginal valuations (e.g. for small changes in wetland area) are less constrained by household income than total valuations (e.g. for total loss of a wetland area) from which we compute average values. Moreover, the expected effect of diminishing marginal values with scale is potentially already captured by the wetland size variable.

\subsection{Wetland Change Due to Climate Change in Europe 2000-2050}

Climate change is expected to have numerous and complex impacts on the provision of ecosystem services from wetlands in Europe. Impacts of climate change on wetlands include changes in hydrology, sea level rise (for coastal wetlands), and temperature rise and variability, which will affect temperature sensitive wetland plant and animal species and water quality. Relatively small changes in precipitation, evaporation, or transpiration, which alter surface or ground water level by only a few centimetres, can be enough to reduce many wetlands in size. Heavy rain events as well as dry spells in western and central Europe are expected to become more intense and lead to more extreme conditions in terms of water level fluctuations. The potential for wetland species to migrate in response to changes in climate is seen as limited (Davis and Shaw 2001).

The anticipated impacts of climate change on wetlands are not all negative and several countervailing effects are expected. Higher carbon dioxide levels in the atmosphere may lead to higher growth rates and biomass accumulation in most plants. In addition, an important adaptation option for dealing with increased risks of river flooding due to climate change is to create more space for large rivers through the rehabilitation of floodplain areas (Duel et al. 1994; Marchand et al. 1995). Such measures are expected to partially restore the size and functioning of floodplain wetlands (Bischoff and Wolter 2001; Buijse et al. 2002).

The effects of climate change on wetlands will impact the provision of wetland services. The spatial distribution of effects, however, will be heterogeneous and dependent on local or regional changes in climatic factors and from the point of departure in the physical/hydrogeographical characteristics of each specific wetland site. Detailed spatially explicit projections for the impacts of climate change on wetlands in Europe are currently unavailable. For the purposes of our case study in value transfer, we therefore describe a general scenario of wetland change in Europe under climate change. Following Nicholls (2004), we assume a rate of wetland loss of $8 \%$ for the period 2000-2050. We are therefore comparing two scenarios of ecosystem service provision from wetlands, one in which the present stock of wetlands is conserved at its 2000 level and an alternative scenario in which the extent of wetland is uniformly reduced by $8 \%$. We assume that this $8 \%$ area change will not drive wetland ecosystems beyond any ecological threshold. It is noted that the impacts of climate change are additional to existing stresses and trends in wetland extent and functioning. The analysis

\footnotetext{
6 The scale at which the population variable is defined is also empirically determined in the meta-analysis and also measured for the area within a $50 \mathrm{~km}$ radius of the centre point of each wetland site.

7 Marginal value estimates are derived from valuation scenarios that describe an incremental change in wetland area, whereas average value estimates are derived from valuations of ecosystem services from the total area of a wetland.
} 


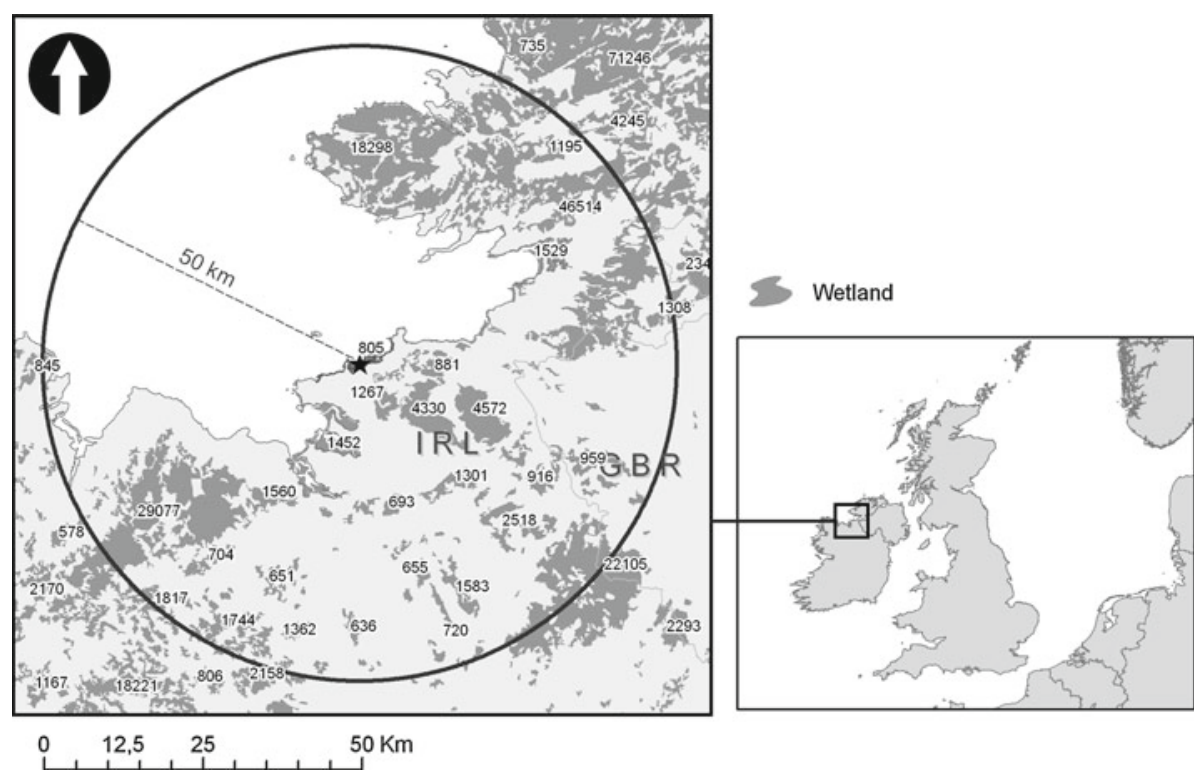

Fig. 2 Example of wetland abundance calculation. Numbers indicate wetland area in hectares

in this study examines only expected changes in wetland extent due to climate change and not due to other causes.

To spatially model wetland ecosystems in Europe we make use of the European Environment Agency's CORINE seamless vector land cover data (Bossard et al. 2000). A GIS is used to obtain information on the physical (ecosystem size, wetland type, wetland abundance) and socio-economic (income, population) characteristics of each wetland site in this data set. The sizes of the areas of individual wetland sites have been calculated with the calculate geometry function in the applied GIS software (ArcGIS from ESRI). We also calculate the centre-points of the areas of the wetland sites.

The wetland abundance variable is defined as the summed area of wetlands within $50 \mathrm{~km}$ of the centre-point of each wetland site. The map in Fig. 2 shows an example of how wetland abundance is calculated for each site. It shows the centre-point of an intertidal mudflat in the Republic of Ireland with a surface of 805 ha, surrounded by 147,406 ha of other wetland areas in a circular $50 \mathrm{~km}$ zone. In the present analysis, the cumulative wetland area within a $50 \mathrm{~km}$ radius is considered, i.e. no distinction is made between different wetland types.

The population in the vicinity of each wetland site (defined within a radius of $50 \mathrm{~km}$ of the centre of each wetland) is calculated using the Gridded Population of the World dataset (GPWv3) of the Socioeconomic Data and Applications Center (SEDAC). The process by which this data can be generated is described in Wagtendonk and Omtzigt (2003). Population growth projections for the EU member states are taken from Corone et al. (2006). These projections are at the national level and do not reflect more refined spatial trends in population change, e.g. migration from rural to urban areas.

The GDP per capita figures for the NUTS2 regions in which each wetland is located were calculated by combining Eurostat statistics for GDP in 2003 at current market prices at NUTS level 2 with the administrative map units downloaded from the EEA data service. Projected 
Table 3 Example numbers used in calculation for an individual wetland in the United Kingdom

\begin{tabular}{lr}
\hline Variable & Value \\
\hline Wetland area in conservation scenario (ha) & 327 \\
Wetland area in climate change scenario (ha) & 301 \\
Wetland abundance in conservation scenario (ha; 50 km radius) & 8,412 \\
Wetland abundance in climate change scenario (ha; 50 km radius) & 7,739 \\
Population 2050 (50 km radius) & $1,264,494$ \\
GDP per capita 2050 (2003 US\$ PPP) & 48,440 \\
Value per hectare in conservation scenario (2003 US\$) & 6,188 \\
Value per hectare in climate change scenario (2003 US\$) & 6,370 \\
Mean per hectare value (2003 US\$) & 6,279 \\
Change in wetland area (ha) & -26 \\
Value of change (2003 US\$) & $-164,255$ \\
\hline
\end{tabular}

growth in GDP for the EU member states for the period to 2050 was taken from Corone et al. (2006).

The CORINE database contains information on 53,743 European wetland sites. It was not, however, possible to generate the spatial variables required for all of these sites due to missing data in some of the data sets used. The number of wetlands for which all spatial variables are available is 50,533 , which is $94 \%$ of the wetlands in the CORINE database.

\subsection{Value Transfer Results}

We use the meta-analytic value function described in Sect. 3.1 to assign site specific per-hectare values to all wetlands under the conservation scenario and the climate change scenario, evaluating them at the projected 2050 population and per-capita incomes, but taking account of the differences in wetland abundance and wetland size between the two scenarios. ${ }^{8}$ In other words, both scenarios are valued from the perspective of beneficiaries in 2050 (population and income levels). The value function is set to estimate marginal values, i.e. the dummy variable distinguishing between marginal and average values is set to 1 . We then multiply the change in area of each wetland with the site specific marginal per-hectare value (i.e. the mean of the marginal per hectare values for the two scenarios for each site).

For the purposes of illustration, Table 3 shows the values of key variables used in the calculation of the value of change in a single wetland in the United Kingdom. Over the period 2000-2050, the wetland reduces in size from 327 to 301 ha (a change of 26 ha). The abundance of wetlands within a $50 \mathrm{~km}$ radius of the wetland also declines slightly over the same period (by definition, also by $8 \%$ ). These values, together with the population within a $50 \mathrm{~km}$ radius and the GDP per capita for the NUTS2 region in 2050, and a dummy indicator of the

\footnotetext{
8 Since we do not have information regarding the wetland ecosystem services provided by each wetland policy site we assume that each wetland provides the average level of ecosystem services observed in the wetland valuation database, i.e. the meta-analytic value function is set to estimate the value of the average level of ecosystem service provision. This assumption may be questioned if the set of study sites are unrepresentative of the set of policy sites in terms of service provision, for example in the case of research priority selection bias (Hoehn 2006). Similarly, we set the meta-analytic value function to estimate the value produced by the average valuation method in the data underlying the meta-regression. The mean values of these explanatory variables are presented in Table 1.
} 
wetland type, are substituted into the meta-analytic value function to estimate per hectare values for the wetland under the conservation scenario (equal to wetland stock in 2000) and the climate change scenario (wetland stock in 2050, $8 \%$ below 2000 level). The changes in area of the wetland site and wetland abundance cause the value per hectare of the wetland to increase slightly from 6,188 to $6,370 \mathrm{US} \$ / \mathrm{ha}^{9}$ (the mean marginal value per hectare between the two scenarios is therefore $6,279 \mathrm{US} \$ / \mathrm{ha}$ ). Multiplying this value by the change in area gives the value of the change: -US\$164,255. Note that this is an annual value, i.e. it is the value of the annual flow of ecosystem services that are lost due to the reduction in wetland size.

Table 4 presents the results for all wetland changes aggregated by country. The annual value in 2050 of lost ecosystem services in Europe resulting from wetland change due to climate change is estimated to be approximately US\$ 1 billion (at 2003 price levels). Lower and upper bound values are calculated using the $95 \%$ prediction intervals for each wetland site, which are computed using the method proposed by Osborne (2000). The prediction intervals provide an indication of the precision with which the estimated value function can predict out of sample values. They do not, however, reflect a number of other sources of uncertainty, which are discussed in Sect. 4.

There is considerable variation in the area of wetland change and the value of this change across European countries. For example, Finland experiences the second highest total loss of wetland area (157,757 ha) but the value of this change (US\$ 34 million) is low relative to other countries due to the abundance of its wetlands and its low population density (low number of ecosystem services beneficiaries). In contrast, Italy experiences a smaller loss of wetland area $(5,511 \mathrm{ha})$ but the value of this loss (€54 million) is considerably higher due to the scarcity of wetlands in Italy and higher population density.

The results of this case study application will be subject to errors for a number of reasons. These include: (a) transfer errors arising from not being able to control for all variation in wetland ecosystem service values using the limited explanatory variables in the meta-analytic value function, (b) inaccuracies in the land use data used to construct the database of European wetland sites, and (c) the simple assumptions used to describe the impacts of climate change on the extent and spatial distribution of wetlands. A general discussion of sources of uncertainty in scaling up values is provided in the next section. The main purpose of the case study, however, is to provide an illustration of the proposed methodology for scaling up values rather than precise estimates of climate change impacts. The case study should be re-examined when better valuation data and more detailed and spatially explicit land use projections become available.

\section{Sources of Uncertainty}

Ideally we would be able to provide a quantified measure that reflects all sources of uncertainty in the analysis, e.g. in the form of an interval around the predicted value and the probability that the true value falls within that range. Computing such prediction intervals, however, requires information on the precision of the data and models used at each stage in the scaling up analysis. It is important to recognise that the analysis involves an aggregation of uncertainties from multiple sources at each step. In this section we identify and discuss the sources of uncertainty that are present in the proposed scaling up approach.

9 Note that the unit value changes by the factor $\exp \{[\ln (1)-\ln (0.92)][0.218+0.125]\}=1.029$. Furthermore, in this value transfer application, in which all wetlands are assumed to uniformly decrease in area by $8 \%$, the per-hectare values of all wetlands change by this same factor. 
Table 4 Number of wetland sites, change in wetland area, and change in value of ecosystem services by country under climate change scenario 2000-2050

\begin{tabular}{|c|c|c|c|c|c|}
\hline Country & $\begin{array}{l}\text { Number of } \\
\text { wetlands }\end{array}$ & $\begin{array}{l}\text { Change in } \\
\text { wetland area } \\
\text { (ha) }\end{array}$ & $\begin{array}{l}\text { Change in } \\
\text { value (millions } \\
\text { US\$) }\end{array}$ & $\begin{array}{l}95 \% \text { lower } \\
\text { bound } \\
\text { (millions US\$) }\end{array}$ & $\begin{array}{l}95 \% \text { upper } \\
\text { bound } \\
\text { (millions US\$) }\end{array}$ \\
\hline Austria & 211 & $-2,540$ & -11 & -10 & -13 \\
\hline Belgium & 92 & -838 & -8 & -6 & -9 \\
\hline Bulgaria & 81 & -927 & -4 & -3 & -4 \\
\hline Croatia & 140 & $-1,501$ & -7 & -6 & -8 \\
\hline Cyprus & 3 & -156 & -1 & -1 & -2 \\
\hline Czech Rep & 105 & -719 & -3 & -3 & -4 \\
\hline Denmark & 729 & $-13,197$ & -46 & -41 & -52 \\
\hline Estonia & 1,146 & $-15,823$ & -15 & -13 & -16 \\
\hline Finland & 14,140 & $-157,757$ & -34 & -30 & -37 \\
\hline France & 1,419 & $-28,653$ & -156 & -147 & -164 \\
\hline Germany & 1,391 & $-33,516$ & -105 & -94 & -116 \\
\hline Greece & 302 & $-5,181$ & -26 & -23 & -29 \\
\hline Hungary & 1,090 & $-7,720$ & -32 & -31 & -34 \\
\hline Ireland & 2,173 & $-96,804$ & -40 & -32 & -49 \\
\hline Italy & 344 & $-5,511$ & -54 & -50 & -58 \\
\hline Latvia & 883 & $-12,526$ & -9 & -7 & -10 \\
\hline Lithuania & 563 & $-4,604$ & -7 & -7 & -8 \\
\hline Malta & 1 & -2 & 0 & 0 & 0 \\
\hline Netherlands & 273 & $-21,580$ & -84 & -63 & -104 \\
\hline Poland & 913 & $-8,831$ & -36 & -33 & -37 \\
\hline Portugal & 162 & $-2,263$ & -24 & -21 & -27 \\
\hline Romania & 1,532 & $-30,769$ & -60 & -57 & -62 \\
\hline Slovakia & 74 & -343 & -3 & -2 & -3 \\
\hline Slovenia & 13 & -260 & -2 & -1 & -2 \\
\hline Spain & 392 & $-9,015$ & -56 & -49 & -63 \\
\hline Sweden & 20,242 & $-218,330$ & -48 & -44 & -52 \\
\hline United Kingdom & 2,119 & $-60,295$ & -144 & -130 & -160 \\
\hline Total & 50,533 & $-739,662$ & $-1,016$ & -905 & $-1,122$ \\
\hline
\end{tabular}

The primary valuation estimates from which the meta-analytic value function is estimated are subject to a number of sources of error. Measurement error in primary valuation estimates may result from weak methodologies, unreliable data, analyst errors, and the whole gamut of biases and inaccuracies associated with valuation methods (Rosenberger and Stanley 2006). Measurement error may also derive from the process by which estimated values are aggregated. Bateman et al. (2006) show that the identification of the constituency of beneficiaries over which WTP estimates are aggregated, and the adjustment of WTP estimates to reflect beneficiary characteristics, can lead to significant errors in resultant aggregate values. Meta-analytic value functions based on this literature are therefore expected to suffer from parameter uncertainty but the quantification of this uncertainty is challenging. Standard errors for the parameters estimated in the meta-analytic value function 
are available but these do not necessarily fully reflect imprecision in the data underlying the analysis.

In addition to measurement error in the underlying valuation literature, the sample of values available in the literature may be biased and unrepresentative (Rosenberger and Johnston 2009). Publication selection bias arises when the publication process through which valuation results are disseminated results in an available stock of knowledge that is skewed to certain types of results and that does not meet the information needs of value transfer practitioners. In the economics literature there is generally an editorial preference to publish statistically significant results and novel valuation applications rather than replications, which may result in publication bias (Rosenberger and Stanley 2006). Similarly, there may be a bias in the available stock of knowledge due to research priority selection, i.e. the implementation of primary valuations at study sites for which there is high awareness and policy interest. Hoehn (2006) shows in a meta-analysis of wetland values that research priority selection can lead to substantial over estimation of mean wetland values in value transfer. See Rosenberger and Johnston (2009) for a review of the available approaches for ameliorating the impacts of selection effects on value transfer.

A further source of uncertainty enters the scaling up analysis at the step of transferring values to the set of policy sites in the form of generalisation error. Generalisation error occurs when values for study sites are transferred to policy sites that are different without fully accounting for those differences (Rosenberger and Stanley 2006). Such differences may be in terms of population characteristics (income, culture, demographics, education, preferences etc.) or environmental/physical characteristics (quantity and/or quality of the good or service, availability of substitutes, accessibility etc.). This source of error is inversely related to the correspondence of characteristics of the study and policy sites (Rosenberger and Phipps 2007). In the context of meta-analytic function transfer, generalisation error can arise due to the common limitation of meta-analyses to capture differences in the quality and quantity of the services under consideration. It is often the case that the provision of goods and services is indicated in a meta-analysis merely with binary variables, and that quality is not captured at all. This limitation may translate into transfer errors since the estimated transfer function cannot reflect important quality and quantity differences in characteristics across sites. A similar problem arises where non-identical services have been combined as one explanatory variable in the meta-analysis. Some level of aggregation across service types is often necessary in order to produce a manageable number of variables in the meta-regression, but at the cost of losing specific categories of services. There may also be a temporal source of generalisation error in that preferences and values for ecosystem services may not remain constant over time. Using value transfer to estimate values for ecosystem services under future policy scenarios may therefore entail a degree of uncertainty regarding whether future generations hold the same preferences as current or past generations. This source of uncertainty is also difficult to quantify. A limited measure of generalisation error can be obtained by examining the differences between observed primary values and predicted values. The meta-analytic value function can be used in a jack-knife or $\mathrm{n}-1$ data splitting exercise to predict the values found in the primary valuation literature and compute mean absolute percentage errors (e.g. Brander et al. 2006). This provides a measure of generalisation error within the sample of primary valuation estimates but does not necessarily represent the full set of policy sites.

The GIS data and spatial modelling underlying the spatial variables included in the value data and the identification and description of policy sites are also subject to a degree of uncertainty. The selection of spatial data followed a set of criteria to identify reliable data sets. These criteria include the consistency, accuracy and credibility of the data. Nevertheless, the requirement for data with a regional coverage necessitates the use of data that is not of the 
highest precision. Sources of imprecision include measurement and analyst errors but also deliberate generalizations, e.g. reclassification of land use classes in a limited number of subclasses. Another potential source of error is the assignment of geographic coordinates to the selected study sites. Depending on the geographic information provided in the primary studies, the centroids of some study sites can be located accurately, whereas others can only be located on much coarser scale.

\section{Conclusions}

The paper proposes a methodology for scaling up values for changes in ecosystem service provision at large geographic scales and illustrates the procedure with a case study on wetland change due to climate change in Europe. The proposed methodology makes use of meta-analytical value transfer to produce a value function that is subsequently applied to estimate values of individual ecosystem sites. Site-specific, study-specific and contextspecific variables are used to define a price vector that captures differences between sites. The proposed method is shown to be practicable and to enable the adjustment of transferred ecosystem service values to reflect the variation in important spatial variables. There are, however, a number of issues that require further discussion and research.

Points of strength of the proposed meta-analytic value transfer technique are its ability to explicitly account for context variables that are relevant in understanding people's perceptions and preferences but are often neglected in primary valuation studies because they are constants of the analysis. Context variables included in the case study aim at assessing the influence of income effects, substitute sites, and population density on wetland values. Their spatial variability is captured on a scale based either on administrative boundaries (as for the variable real GDP per capita) or distance from the ecosystem centre (as for wetland abundance and population density). Importantly for scaling up ecosystem service values, the proposed approach enables us to adjust site specific marginal values for changes in the provision of ecosystem services from the rest of the ecosystem stock.

An important area for improvement in the proposed value transfer method is the treatment of ecosystem quality. As currently proposed, the method deals primarily with the quantity or area of ecosystems and does not deal well with changes in quality. To incorporate ecosystem quality in the value transfer process would require the definition and inclusion of quality variables in both the valuation data underlying the meta-analysis and in the data on ecosystem networks to which values are transferred. In the case of wetlands, several methods are available for assessing their ecological integrity (Fennessy et al. 2004). Most of them, however, are not practicable for the type of analysis that the present study aims at as they rely on local biological, physical and chemical measurements which are not available for most of the study and policy wetland sites. Some methods, however, use estimates of the anthropogenic pressures in the area surrounding the wetland as a proxy for its ecological status assuming that this strongly depends on them. Such methods are usually referred to as landscape assessments.

A further limitation of our proposed method is that it does not differentiate between services to take account of different demand and supply characteristics. In terms of demand, population and income effects are treated the same across all services. Regarding supply, we implicitly assume that the provision of all ecosystem services is equally proportional to the geographical size of the ecosystem sites. A service-specific value transfer approach could take account of such differences, but this would require service specific meta-analytic value functions. It is, however, unlikely that the current availability and quality of primary 
valuation data would allow for the estimation of such specific meta-analytic value functions. The potential for using meta-analysis to estimate service specific value functions will improve as more primary valuation data become available.

A related issue that requires further work is the incorporation of missing components of economic value in estimating ecosystem values. Value transfer is inevitably restricted by the availability of primary valuation studies for the specific ecosystems and services of policy interest. While there may be a large and growing number of ecosystem service valuation studies available, there are still gaps in the knowledge. In the case of wetlands, there are very few valuation studies that explicitly capture only non-use values. Filling such gaps in the available value information would require targeted primary valuation studies.

We recognise and discuss a large range of issues that introduce limitations and errors in the use of meta-analysis for scaling up values but it is the intention of this paper to move the debate forward on policy relevant value transfer applications. In response to growing political demand, there will be an increasing number of "up scaling" exercises in the near future. For example, the Convention on Biodiversity New Strategic Plan for 2020 requests that values for biodiversity be integrated into national development strategies and national accounts. Similarly, the EU Biodiversity Strategy for 2020 (Target 2, Action 5) requires Member States to assess the economic value of ecosystem services and integrate them into accounting systems at the national level. In addition, many countries are currently conducting assessments of the value of their ecosystems following the example set by the TEEB study. The approach proposed in this paper will help to give these studies a methodologically more robust basis.

Acknowledgments This research has, in part, been funded by the European Environment Agency under contract 3603/B2008/EEA.53405 (2009). The authors are grateful to four anonymous reviewers for useful comments and suggestions on this paper.

Open Access This article is distributed under the terms of the Creative Commons Attribution Noncommercial License which permits any noncommercial use, distribution, and reproduction in any medium, provided the original author(s) and source are credited.

\section{References}

Bateman IJ, Day BH, Georgiou S, Lake I (2006) The aggregation of environmental benefit values: welfare measures, distance decay and total WTP. Ecol Econ 60:450-460

Bischoff A, Wolter C (2001) The flood of the century on the river Oder: effects on the 0+ fish community and implications for floodplain restoration. Regul Rivers Res Manag 17:171-190

Bockstael NE, Freeman AMIII, Kopp RJ, Portney PR, Smith VK (2000) On measuring economic values for nature. Environ Sci Technol 34:1384-1389

Bossard M, Feranec J, Otahel J (2000) CORINE land cover technical guide-Addendum 2000. European Environment Agency technical report No. 40

Braat L, ten Brink P (eds) (2008) The cost of policy inaction: the case of not meeting the 2010 biodiversity target. Alterra, Wageningen, The Netherlands

Brander LM, Florax RJGM, Vermaat JE (2006) The empirics of wetland valuation: a comprehensive summary and a meta-analysis of the literature. Environ Res Econ 33:50-223

Buijse AD, Coops H, Staras M, Jans LH, van Geest GJ, Grift RE, Ibelings BW, Oosterberg W, Roozen FCM (2002) Restoration strategies for river floodplains along large lowland rivers in Europe. Freshw Biol 47:889-907

Corone G, Denis C, McMorrow K, Mourre G, Roger W (2006) Long term labour productivity and GDP projections for the EU25 Member States: a production function framework. European Commission Directorate-General for Economic and Financial Affairs. Economic Papers No. 253 
Costanza R, d'Arge R, de Groot R, Farber S, Grasso M, Hannon B, Limburg K, Naeem S, O’Neill RV, Paruelo J, Raskin RG, Sutton P, van den Belt M (1997) The value of the world's ecosystem services and natural capital. Nature 387:253-260

Davis MB, Shaw RG (2001) Range shifts and adaptive responses to quaternary climate change. Science 292:673-679

Downing M, Ozuna J (1996) Testing the reliability of the benefit function transfer approach. J Environ Econ Manag 30:22-316

Duel H, Denneman WD, Kwakernaak C (1994) Ecological models for rivers floodplain rehabilitation. Water Sci Technol 29:383-386

Eshet T, Baron MG, Shechter M (2007) Exploring benefit transfer: disamenities of waste transfer stations. Environ Resour Econ 37:47-521

Fennessy MS, Jacobs AD, Kentula ME (2004) Review of rapid methods for assessing wetland conditions. EPA/620/R-04/009. US Environmental Protection Agency, Washington, D.C., USA

Fisher B, Turner RK, Zylstra M, Brouwer R, De Groot R, Farber S, Ferraro P, Green R, Hadley D, Harlow J, Jefferiss P, Kirkby C, Morling P, Mowatt S, Naidoo R, Paavola J, Strassburg B, Yu D, Balmford A (2008) Ecosystem services and economic theory: integration for policy-relevant research. Ecol Appl 18:2050-2067

Ghermandi A, van den Bergh JCJM, Brander LM, de Groot HLF, Nunes PALD (2010) The economic value of wetland conservation and creation: a meta-analysis. Water Resour Res 46:1-12

Hoehn JP (2006) Methods to address selection effects in the meta regression and transfer of ecosystem values. Ecol Econ 60:389-398

Johnston RJ, Besedin EY, Iovanna R, Miller CJ, Wardwell RF, Ranson MH (2005) Systematic variation in willingness to pay for aquatic resource improvements and implications for benefit transfer: a meta-analysis. Can J Agric Econ 53:48-221

Johnston RJ, Rosenberger RS (2009) Methods, trends and controversies in contemporary benefit transfer. J Econ Surv 24:479-510

Kirchhoff S (1998) Benefit function transfer vs. meta-analysis as policy-making tools: a comparison. In Proc. of Workshop on Meta-Analysis and Benefit Transfer: State-of-the-art and Prospects. Tinbergen Institute, Amsterdam

Marchand M, Marteijn ECL, Bakonyi P (1995) Policy analysis as a tool for habitat restoration: a case study of a Danube river floodplain, Hungary. Water Sci Technol 31:179-186

Millennium Ecosystem Assessment (2005) Ecosystems and human well-being synthesis. Island Press, Washington, DC

Moeltner K, Boyle KJ, Paterson RW (2007) Meta-analysis and benefit transfer for resource valuation addressing classical challenges with Bayesian modelling. J Environ Econ Manag 53:250-269

Mullan K, Kontoleon A (2008) Benefits and costs of forest biodiversity: economic theory and case study evidence. Report prepared for IUCN

Navrud S, Ready R (2007) Environmental value transfer: Issues and methods. Springer, Berlin

Nelson JP, Kennedy PE (2009) The use (and abuse) of meta-analysis in environmental and resource economics: an assessment. Environ Resour Econ 42:345-377

Nicholls RJ (2004) Coastal flooding and wetland loss in the 21st century: changes under the SRES climate and socio-economic scenarios. Glob Environ Chang 14:69-86

Osborne JW (2000) Prediction in multiple regression. Practical Assessment, Research \& Evaluation, 7. ISSN 1531-7714

Perrings C, Pearce DW (1994) Threshold effects and incentives for the conservation of biology. Environ Resour Econ 4:13-28

Ready R, Navrud S (2006) International benefits transfer: methods and validity tests. Ecol Econ 60:429-434

Rosenberger RS, Phipps TT (2007) Correspondence and convergence in benefit transfer accuracy: A metaanalytic review of the literature. In: Navrud S, Ready R (eds) Environmental values transfer: issues and methods. Springer, Dordrecht

Rosenberger RS, Stanley TD (2006) Measurement, generalization, and publication: Sources of error in benefit transfers and their management. Ecol Econ 60:372-378

Rosenberger RS, Johnston RJ (2009) Selection effects in meta-analysis and benefit transfer: Avoiding unintended consequences. Land Econ 85:410-428

Scheffer M, Carpenter S, Foley JA, Folke C, Walkerk B (2001) Catastrophic shifts in ecosystems. Nature 413:591-596

Shrestha R, Rosenberger R, Loomis L (2007) Benefit transfer using meta-analysis in recreation economic valuation. In: Navrud S, Ready R (eds) Environmental value transfer: issues and methods. Springer, Dordrecht, The Netherlands 
Smith VK, Pattanayak SK (2002) Is meta-analysis a Noah's Ark for non-market valuation?. Environ Resour Econ 22:271-296

Stern N (2007) The economics of climate change: the Stern review. Cambridge University Press, Cambridge, UK

TEEB (2010) The economics of ecosystems and biodiversity: ecological and economic foundations. Kumar P (ed). Earthscan, London and Washington

Turner RK, Paavola J, Cooper P, Farber S, Jessamy V, Georgiou S (2003) Valuing nature: lessons learned and future research directions. Ecol Econ 46:493-510

Wagtendonk A, Omtzigt N (2003) Analysis of population density around wetland areas in GPW (Gridded Population of the World) files. SPINlab document. Institute for Environmental Studies, Amsterdam, The Netherlands 